\title{
EDITORIAL
}

\section{EN RECUERDO DE GONZALO PIÉDROLA GIL}

\author{
Ministerio de Sanidad y Consumo.
}

El pasado día 19 de noviembre de 1996 fallecía en su domicilio de Madrid D. Gonzalo Piédrola Gil, sin más enfermedad previa que los mínimos achaques propios de su edad. Al terminar de ver un programa sencillo de televisión de los que a él le gustaban, perdía el conocimiento y se le paraba súbitamente su corazón que tan intensamente había funcionado durante casi 90 años. Los hubiera cumplido el 2 de abril. Una muerte sin sufrimiento, plácida, digna del gran maestro de la Salud Pública que se nos iba en ese momento.

D. Gonzalo nació en Granada, donde estudió el bachillerato en el Instituto Padre Usares, con premio extraordinario. En esta ciudad cursó entre 1923 y 1930 la Licenciatura de Medicina, con el broche de premio extraordinario que bien merecía su brillantísimo expediente. Esta misma calificación volvió a obtener en el doctorado por la Universidad Complutense.

Casado con Doña María, granadina que le dio dos hijos también nacidos en Granada, M. ${ }^{a}$ Magdalena y Gonzalo, constituyeron un matrimonio ejemplar por su cariño, cristiana concepción de la vida en todos sus aspectos y por la colaboración continua que mantuvieron en sus más de 50 años de matrimonio. Doña María fue esposa y madre ejemplar, además de secretaria del profesor: varias ediciones del «libro», así como innumerables publicaciones, conferencias y artículos, fueron escritas por ella, en su doble faceta de asesora y mecanógrafa.
En una breve nota bibliográfica sobre D. Gonzalo es imposible abarcar todos los aspectos del hombre tímido, afectivo, respetuoso y magistral que fue. Un gran hombre, con una gran humanidad. En un resumen de su vida para una revista científica, es obligatorio citar los aspectos más sobresalientes de las tres facetas más importantes de su vida: la profesional, la docente y la investigadora, así como el de creador de ciencia.

Profesionalmente, tras una completa y larga formación como Oficial Sanitario, Jefe médico de Sanidad Nacional, médico militar y diplomado en Medicina Preventiva del Ejército, becario ayudante del Instituto Pasteur y su dura formación médica asistencial como teniente médico en Marruecos, ocupó puestos de trabajo en los que destacó su gran labor sanitaria: fue Médico Militar en el Instituto de Higiene del Ejército, al que contribuyó a cambiarle definitivamente el nombre por el de Instituto de Medicina Preventiva «Capitán Médico Ramón y Cajal». Durante muchos años fue Jefe de la Sección de Vacuna Antivariólica, en la que se producía ésta por escarificación en la piel de «ternera rubia gallega», linfa con la que jamás hubo problemas. En este mismo centro fue Jefe de Estudios y Coronel Director hasta su ascenso a General, destino que ejerció en la IV Región.

Como médico de Sanidad Nacional fue responsable en la Dirección General de Sanidad de la Sección de Gerocultura, Geriatría y Protección contra las Radiaciones Ionizantes, posteriormente pasó a su destino en la Escuela 
Nacional de Sanidad, donde sucesivamente fue jefe del laboratorio de Parasitología, jefe de Estudios y Subdirector.

Otros aspectos asistenciales en los que destacó su labor fueron los que desempeñó como jefe de sección de Parasitología del Consejo Superior de Investigaciones Científicas, jefe del Laboratorio de Investigaciones Clínicas de la Facultad de Medicina de Madrid, y jefe del Servicio de Medicina Preventiva del Hospital Clínico de Madrid, siendo en esta faceta, como en otras muchas, pionero en el desarrollo de su actividad.

Como docente, D. Gonzalo, como le llamaban sus alumnos y discípulos, enseñó en el Ejército y en la Escuela Nacional de Sanidad, y como profesor en Medicina, Farmacia, Instituto Social de la Mujer, Escuelas de Enfermería, etc. Fue profesor adjunto de la Facultad de Medicina de Madrid, Catedrático por oposición de Microbiología y Parasitología e Higiene y Sanidad en la Facultad de Medicina de Granada y Catedrático de Higiene y Sanidad (Medicina Preventiva y Social) en la Facultad de Medicina de Madrid. Él elevó la Medicina Preventiva a la categoría de disciplina importante en nuestro país. Además de sus miles de alumnos de las distintas diplomaturas y licenciaturas en las que ejerció su magisterio, D. Gonzalo tuvo innumerables discípulos directos: los que formó como especialistas en Medicina Preventiva en el Instituto «Capitán Médico Ramón y Cajal», los Diplomados, Oficiales Sanitarios y Médicos de Sanidad Nacional de la Escuela Nacional de Sanidad, los profesores formados a su lado en la Facultad de Medicina, y los discípulos de estos que fueron a su vez enseñados por él y que cariñosamente le llamaban «El abuelo».

La gran pléyade de discípulos del gran maestro de la Salud Pública española que fue D. Gonzalo la constituyen los anónimos: inspectores del seguro, médicos militares, y sobre todo los sanitarios locales que aprendieron la Salud Pública estudiando todas y cada una de las ediciones de «su libro», que, los más entusiastas tenían en lugar destacado de su biblioteca y los menos en un lugar no visible. Ellos, los no conocidos, fueron los que más aprendieron y pusieron en práctica las enseñanzas del Maestro.

Como investigador y creador de ciencia, tres son las facetas en las que destaca la dilatada y fecunda tarea del profesor Piédrola: sus artículos científicos, su «libro», y sus comunicaciones y publicaciones en la Real Academia Nacional de Medicina.

Sus numerosos artículos científicos trataron en su dilatada experiencia los múltiples temas que iban siendo actualidad científica: vacunas, insecticidas, lucha contra las enfermedades parasitarias, desinfectantes, radiaciones, catástrofes, organización y planificación sanitaria, tercera edad, y otros muchos problemas de gran trascendencia sanitaria.

La obra más conocida como creador y transmisor de ciencia de D. Gonzalo es su libro de Medicina Preventiva y Salud Pública, el «Piédrola», que a lo largo de sus nueve ediciones ha ido transmitiendo y actualizando los conocimientos de la especialidad; compartió su obra con la mayor parte de los profesores de todas las Universidades españolas, con él han aprendido la Salud Pública casi todos los alumnos, profesores y especialistas españoles. Durante mucho tiempo fue la obra en castellano de la especialidad. Con ella ha contribuido D. Gonzalo, más que ningún otro autor, al desarrollo de la Salud Pública.

A su jubilación, el Profesor Piédrola Gil, además de escribir su libro, dedicó su esfuerzo científico a la Real Academia Nacional de Medicina, en ella produjo gran número de publicaciones, preferentemente sobre temas geriátricos, ecológicos, el tercer y cuarto mundo, la adolescencia y juventud, edades a las que dirigió sus últimas publicaciones, pues sus problemas y su desorientación le preocupaban enormemente.

Ha muerto un gran Maestro de la Medicina Preventiva y la Salud Pública, descanse en paz. 